\title{
The Challenge of the New Generation- Sustainable Consumption \& Production
}

\author{
Peiris VSR
}

\begin{abstract}
President-Lanka Responsible Care Council and Immediate Past President- Asia Pacific Roundtable for
\end{abstract} Sustainable Consumption and Production

\section{INTRODUCTION}

Over exploitation of natural resources due to population explosion, urbanization and changing life style is a common problem across the globe. The ecological foot print of a living individual in most parts of the world exceeds the fair share. This indicates that we are heading towards disaster due to environmental problems emerging as a result of the over consumption of resources. The resulting environmental problems appear in disguised forms of natural calamities, health related issues, dearth of resources etc. It is surprising but sad that less than $20 \%$ of the global population is living in abundance while the majority live in the midst of shortages.

The Asia Pacific represents a specific segment of global population with special identities. The region is rich in natural resources but a majority of the world's poor live in this region. The extremely rich and extremely poor people coexist in the Asia Pacific region especially in the developing countries. Besides, a number of tribes and nations having centuries old cultures and civilizations live in the region.

\section{CONCEPT OF SUSTAINABLE CONSUMPTION AND PRODUCTION}

Though Sustainable Consumption and Production is a phrase coined recently we can retrace our foot steps back to the past to re learn from the ancestors of these old civilizations about the sustainable coexistence of human beings, whether rich or poor, with the environment. Most of these old cultures had a number of sustainable practices, which we can adopt today to suit our changing needs. If we carefully analyze the practices of our ancestors, we can find the modern concepts like Cleaner Production and Life Cycle Thinking embedded in all their practices.

Individuals alone cannot achieve sustainable consumption and production. While each one's life style can make a very small contribution, the entire countries and nations have to recognize this fact and develop their national economic plans with this ultimate objective in mind. The journey towards sustainable consumption \& production necessitates the combined efforts of international organizations, donors, national 
governments and people organizations to be synchronized. Pulling in different directions for fulfilling individual goals \& objectives is going to make the situation worse.

We have to recognize the fact that the poverty is a pressing problem and the poor demand more resources to meet their basic needs. The scarcity of limited resources places a premium price on goods and services and this tend to widen the gap between the rich and poor. The cheap imitations and the duplicates with short life spans fill in the vacuum to satiate the needs of the poor. These products consume a huge amount of non-renewable natural resources and designed without any consideration of their life cycle. The national and sub national economic policies should address these aspects, for a nation to journey towards sustainable consumption $\&$ production.

Theoretically, reaching goals of sustainable development is easy, but in practice it is a gigantic task. A simply developed plan by a group of planners sitting in an air-conditioned office cannot help to meet the aspirations of the global population. Everybody knows that the world population is increasing rapidly and it is estimated that it will be in excess of 9 billion by 2050. Each and every human being born to this earth expects to meet his development needs at the expense of others. Only a minority will think of the other living beings and the plant life allowing fulfilling their needs also from the very same resource base.

\section{USE, MISUSE AND ABUSE OF RESOURCES}

Meeting the needs of every human being without due consideration to natural ecological systems can bring disaster to the human and the environment. Paying lip service to the protection of the environment and bio diversity does not help neither the mankind nor the others living species. It is important that every person understands the fragility of the ecological systems in relation to impacts caused by him. Today the life on earth is in grave danger not because of actions of any other species. The main cause for the doom is the actions of man himself. It is true that cosmic actions too play a role in the changes of the earth but the over consumption of resources is considered the main contributing factor for the degradation of the living systems.

The over consumption of resources is one side of the coin. The generation of wastes through production and consumption and their disposal to the earth is the other side. The earth serves as a sink for the disposal of wastes generated by all living species. Except the humans all other species dispose only their excreta and dead carcasses to this huge sink and it has its own mechanisms to assimilate this waste and digest within a short period and convert it to other useful resources. This has been the case even with humans before the industrial revolution in Europe changed the scenario. While the discovery of coal spurred the industrial revolution, the finding of liquid petroleum in the turn of the twentieth century accelerated the modern technological and economic development.

The petroleum based technological revolution made the humans turn to materialism. As a result resource requirement of each individual has grown manifold. This in turn has increased the quantity of waste generated causing the sink to overflow. Today, the natural ecological balance has been disturbed and earth has failed to digest and rejuvenate the wastes received by it within a reasonable time limit. The accumulation of these wastes has caused a severe stress on the air, water and the soil, which serves as the media for transporting these waste streams.

To make the matters further aggravated the scientists invented many new chemicals, which were useful to humans for improving their life style, but caused great dangers to the eco systems through their hazardousness. The current environmental problems such as ozone 
depletion, climate change, acid rain as well as degradation of water quality and soil condition are direct result of the excessive quantity of wastes and their hazardousness. The combined negative impacts of these problems and the other pollution sources are instrumental in the disappearance of many living species, fauna \& flora, health hazards, food insecurity, water scarcity and a plethora of other threats to human life.

\section{SOLUTIONS ARE STILL UNSUSTAINABLE}

Over the last four decades many have tried a multitude of solutions to combat the negative impacts of the excess waste and found nothing works other than reducing the total waste discharged to earth. How can one reduce the wastes discharged to the earth? The only is way by changing the current patterns of production and consumption. The change leads to sustainability of the earth and the eco systems and we define this change as sustainable consumption and production.

Human needs are multiple and complex mainly to satisfy their ever increasing demands of products and services. In the past people tried to satisfy their hunger by consuming a meal. Today a meal does not mean satisfying their hunger only. Instead it represents social status, comfort, convenience as well as his access to wealth. Today many have moved from home cooked meals to restaurants purely as a business strategy.

Many believe that moving among the society who roams the restaurants gives them a business advantage. The associated health costs, social rifts and environmental impacts of this bloated life styles are not fully evaluated by any researcher so far.

In the ancient past our ancestors preserved the excess foods using very simple, energy efficient, non-chemical techniques and technologies that were very environmentally friendly. Today also we preserve our foods but the purpose and the methods of preservation have changed. The busy lifestyle of the modern day humans does not permit spending lot of time to prepare their foods for consumption. Therefore many have resorted to consume preprocessed and packed food, which are termed instant foods. Most of these processed foods needs to be stored under refrigerated conditions thus making them energy dependent. The processing is mostly done using chemicals and artificial ingredients.

The every facet of modern life of many urban human populations is similar to food consumption. They are artificial, energy and resource dependent and complex. This is no different is our country as well. Not only the rich but also the middle class urban population too is victims of this vicious life style. Little they understand that their consumption-oriented life style is not sustainable in the long run as it imposes a severe stress on the environment, which is an essential element of our future survival. Environment patiently absorbs all what we discharge as wastes but the natural reactions taking place due to excessive discharges hit back not only the consumers but also all human beings as well as all living beings. The minor catastrophes such as acid rains, ice melting, floods and water stress are just symptoms of the full-scale catastrophes we are going to experience in the near future. However developed we are scientifically and technologically we have failed to develop effective solutions to combat these catastrophes when they hit us.

\section{STEERING TOWARDS A NEW PARADIGM}

It is for sure that we cannot undo the damage what we have already done. The generations living in the next two or three centuries will face the brunt of the environmental reactions caused by our doings. Still it is not too late for us to delay and mitigate these future impacts if we understand and change wisely. The time for 
action has immerged. What are the things we can do?

First of all we have to understand the situation we are in. The excessive exploitation of natural resources on one side and excessive production of wastes are major causes for these future catastrophes. The population explosion and our extravagant life style are the reasons why we extract resources and produce wastes. No Government can stop the population explosion in the short term. Appropriate strategies and incentives are necessary elements of a population control policy. The government has to obtain the support of the other organizations and individuals to formulate strategies and incentives. We have to remember that poverty and illiteracy are key factors for population rise. The wise management of child and adult education can lead people from this poverty and illiteracy trap.

Sometimes the wrong application of education leads to more consumption. The conventional educational systems associate economic development with materialistic consumption. De-linking of the development from consumption also can be achieved through education only. This necessitates innovative approaches by educational policy makers in combining the sustainability and associated principles with conventional job oriented education and immediate implementation of reforms.

The changing of life patterns of people is the most difficult. The modern day communication channels and its misuse by marketing and advertising personnel have made this doubly difficult. Rules, regulations and policies only cannot change the life patterns. The educated have spent more on consumption and whenever the have-nots progress to haves they move from less consumption to more consumption.

The latent dimension of human values ignored in the midst of materialistic consumption oriented development needs to be given a new thrust if we need to change the life patterns to more sustainable style. The humans do not like to go in circles. They move up in a development spiral. The copying of the solutions of the past cannot give us solutions to modern day problems. We have to learn from the past. The sustainability principles of the past are still valid but the methods may not be applicable today. We have to mix the principles with action suited for modern world if we want to progress towards sustainability.

\section{SATIABILITY LEADS TO SUFFICIENCY}

This brings us to another dimension of social stigma: The concept of satiability. The achievement of sustainability becomes a reality only if the productivity and satiability are fully realized. The current approach of resource conservation and waste minimization at individual level will be inadequate to protect the world from its impending disaster. Satiability of individuals as well as of the society is essential if we want to ensure the future survival of the world.

In very simple terms satiability means being satisfied with the state of the affairs. For example, why people use private vehicles to meet their mobility needs? The reason is they cannot be dependent upon the public transport systems in meeting their needs adequately and timely. When the basic premises of satiability cannot be met by any existing system the humans try to find an alternative which fulfils these basic premises. The urbanization makes it easy to introduce novel techniques and technologies to enhance satiability without exploiting the natural resources.

According to sustainable consumption and production principles, we have to reduce resource intensity of products and recover resources from post-consumer goods. Eco Efficiency strategies can be used to achieve these goals. The products need to be redesigned to eliminate use of non-renewable resources including fossil fuels. 


\section{CONCLUSION}

None of these will be effective unless we change our consumption patterns using smart consumption strategies. The change will come only when we understand that our quality life is not dependent on using more and more resources. The national policies should drive our economic systems to decouple our wellbeing from consumption. Only then we will be able to travel along the path of Sustainable Development to achieve equitable development for us and our progeny.

\section{REFERENCES}

COLIN B. No Impact Man. $1^{\text {st }}$ Edition. New York, Farrar, Straus and Giroux. 2009.

FADEEVA Z, PAYYAPPALLIMANA U, PETRY R \& DIRKSEN A. Innovation in Local and Global Learning Systems for Sustainability: Towards More Sustainable Consumption and Production Systems and Sustainable Livelihoods - Learning Contributions of the Regional Centres of Expertise on Education for Sustainable Development.

GRAAF JE, WANN D \& NAYLOR TH. Affluenza: How Overconsumption Is Killing Us-and How to Fight Back. $3^{\text {rd }}$ Edition. California, Berrett Koehler Publishers Inc. 2014.

LOREK S \& FUCHS D. Strong sustainable consumption governance e precondition for a degrowth path? Journal of Cleaner Production. 2011. DOI:10.1016/j.jclepro.2011.08.008

Paving the way for sustainable consumption and production. The Marrakech process progress report.

PRINCEN T. Logic of Sufficiency. $1^{\text {st }}$ Edition. London, MIT Press. 1951.

World Business Council for Sustainable Development, A vision for sustainable consumption. Innovation, collaboration and the management of choice. 2011. 